$\xi=$

\title{
Ameliorative effects of grape seed proanthocyanidins on cadmium induced metabolic alterations in rats
}

\author{
NazimaBashir, Vaihundam Manoharan, Selvaraj Milton Prabu * \\ Faculty of science, Department of zoology, Annamalai University, Annamalai Nagar \\ *Corresponding author E-mail: smprabu73@gmail.com
}

\begin{abstract}
Objective: To study the ameliorative effects of grape seed proanthocyanidins (GSP) against cadmium (Cd) induced hyperglycemia, hypercholesterolemia and hyperlipidemia in rats.

Methods: Wistar rats, body weight 180-200g, were randomly divided into four groups, six rats in each group. First group (control) represented the control animal, the second group (Cd) was fed orally with Cd in the form of $\mathrm{CdCl}_{2}(5 \mathrm{mg} / \mathrm{kg}$ bw), the third group (GSP) was fed with GSP (200 mg/kg bw) and to the fourth group (Cd+GSP), $\mathrm{CdCl}_{2}$ was administered orally at a dose of (5 $\left.\mathrm{mg} / \mathrm{kg} \mathrm{bw}\right)$ and $\mathrm{pre}-$ treated with GSP (200 mg/kg bw) $90 \mathrm{~min}$ before Cd intoxication for 4 weeks. At the end of experiment, rats were sacrificed; blood and liver samples were collected and used for analysis of various metabolic parameters.

Results: The result of the present study revealed that $\mathrm{Cd}$ exposure caused significant reduction in food intake and body weight gain, but increased the liver weight. GSP administration significantly revert all these changes to normal level. Cd intoxication induced hyperglycemia, elevate plasma glucose and lipid profiles and decline in high density lipoprotein (HDL) -cholesterol respectively. The GSP pretreatment regimen was beneficial in the restoration of the increased serum levels of TC, TG and lipid profiles and of the suppressed insulin and total antioxidants on Cd exposure.

Conclusion: From the present investigation, it may be concluded that $\mathrm{Cd}$ intoxication caused deleterious effects on the metabolism of rats which were successfully restored by GSP. Therefore, the present work suggests that GSP is a feasible therapeutic agent to improve and treat patients with hyperlipidemia, obesity, hyperglycemia in addition to its anti-oxidant properties and can be used as a component in food to promote the health of people.
\end{abstract}

Keywords: Cd, GSP, Carbohydrate Metabolism, Lipid Metabolism, Liver.

\section{Introduction}

Cadmium (Cd) is one of the most important environmental and occupational metallic toxicant arising primarily from battery, electroplating, pigment, fertilizer industries and cigarette smoke. Since $\mathrm{Cd}$ does not degrade in the environment, the risk of human exposure is constantly increased due to $\mathrm{Cd}$ as it also enters the foodchain (ATSDR, 2005). Exposure to Cd produce both acute and chronic tissue injury and can damage various organs and tissues, including liver, kidney, lung, bone, testis and blood, depending on the dose, route and duration of exposure (Sarkar et al., 1995) One of the basis of Cd toxicity is its negative influence on Cd enzymatic systems of cells, owing to the substitution of other metal ions (mainly $\mathrm{Zn}^{2+}$ and $\mathrm{Cu}^{2+}$ ) in metalloenzymes and its very strong affinity to biological structures containing $\mathrm{SH}$, carboxyl and phosphate group (Timbrell.,2000). Exposure to Cd metal is known to induce the formation of reactive oxygen species (ROS) like superoxide radicals, hydroxyl ion and hydrogen peroxide (Stohs et al., 2000) They inhibit many enzymes and disturb many processes, including lipid metabolism and alters in the serum and tissue concentration of some lipid compounds, including free fatty acids (FFA), triglycerides (TG), phospholipids as well as total cholesterol and high and low density lipoprotein cholesterol (HDL and LDL) causing hypercholesterolemia and hyperlipidemia (Larregle et al., 2008)
Grape seed proanthocyanidins (GSP) are polyphenolic compounds that can be found in the plant physiology of various plant species, are mainly concentrated in tree barks and outer skin of the seeds. GSP is of a diphenylpropane structure of $\mathrm{C}_{6}-\mathrm{C}_{3}-\mathrm{C}_{6}$. Most often found as a glycoside derivative, this compound class is composed of three monomer units of catechin, epicatechin, and epigallocatechin (Harborne and Mabry., 1982) GSP can clear off free radicals, protect the over-oxidative damage and prevent a range of diseases caused by free radicals, such as myocardial infarction, atherosclerosis, drug-induced liver and kidney injury more, it has functions of anti-thrombotic, anti-tumor, antimutagenic, anti-radiation, and anti-fatigue (Engelbrecht et al., 2007). GSP has been shown to inhibit lipid peroxidation, platelet aggregation, capillary permeability and fragility and to affect enzyme systems, including phospholipase $A_{2}$, cyclooxygenase and lipooxygenase (Robert et al., 1990). Oral administration of GSP significantly reduces the postprandial levels of TG-rich and apolipoprotein-B-containing lipoproteins and improves several atherosclerotic risk indexes in normolipidemic rats (Delbas et al., 2005). We have studied the protective role of GSP on cadmium induced hepatic dysfunction in rats (Nazimabashir et al., 2014) now the present study was devoted to investigate the influence of (GSP) on some metabolic and biochemical changes associated with hyperglycemia, antihyperlipidemic and antiperoxidative effect on cadmium intoxicated rats. 


\section{Material and methods}

\subsection{Animals}

This study was carried out in 4-5 weeks old male albino Wistar rats, body weight of 180-200 g bred in the Central Animal House, Rajah Muthiah Medical College Annamalai University, India. The animals were housed six per each polypropylene cage and were maintained in accordance with the guidelines of the National Institute of Nutrition, Indian Council of Medical Research Hyderabad, India. The rats were allowed standard rat pellet diet (Lipton India Ltd., Mumbai, India) and water ad libitum. The study protocol was approved by the Institutional Animal Ethical Committee (Vide No $1020,2013)$, for the purpose of control and supervision of experiments on animals CPCSEA at Annamalai University, Annamalainagar India.

\subsection{Chemicals}

GSP (batch no. 005004) was obtained from Inter Health Nutraceutical, Inc. (Benicia, CA, USA). GSP is a natural extract containing approximately 54\% dimeric, $13 \%$ trimeric, and $7 \%$ tetrameric proanthocyanidins. Cadmium Chloride $\left(\mathrm{CdCl}_{2}\right)$ and other fine chemicals were obtained from Pfizer, India. All other chemicals and biochemicals were of analytical grade obtained from local firms.

\subsection{Experimental design}

The total rats were randomly divided into 4 equal groups, each of six rats $1^{\text {st }}$ control group; $2^{\text {nd }}$ GSP $(200 \mathrm{mg} / \mathrm{kg} /$ day $)$ dissolved in saline, $3^{\text {rd }}$ cadmium group $(5 \mathrm{mg} / \mathrm{kg} / \mathrm{day})$ administered through saline; $4^{\text {th }}$ Rats received GSP orally (dissolved in saline) at a dose of $200 \mathrm{mg} / \mathrm{kg}$ day and $\mathrm{Cd}$ was administered orally at a dose of 5 $\mathrm{mg} / \mathrm{kg} /$ day $90 \mathrm{~min}$ after the administration of GSP for 4 weeks. At the end of the experimental period, animals were fasted overnight and sacrificed under mild ether anesthesia. Blood was collected by cardiac puncture; plasma was separated by centrifugation and stored at low temperature. The liver tissue was dissected out, weighed and washed using ice cold saline to remove the blood Tissue was minced and homogenized $(10 \% \mathrm{w} / \mathrm{v})$ in $0.025 \mathrm{M}$ Tris$\mathrm{HCl}$ buffer ( $\mathrm{pH} 7.4)$, and centrifuged (3000 x g for $10 \mathrm{~min})$. The resulting clear supernatant was used for various biochemical assays.

\subsection{Analytical procedure}

2.4.1. Plasma glucose, hepatic glycogen, hepatic hexokinase and G-6-Pase activities

Plasma glucose levels were measured by standard kit (Eve's Inn Diagnostics, India). Rats were sacrificed by decapitation, livers were extracted. Frozen livers were thawed, weighed, and homogenized in Tris- $\mathrm{HCl}(5 \mathrm{mmol} / \mathrm{L}, \mathrm{pH} 7.4)$ buffer containing $2 \mathrm{mmol} / \mathrm{L}$ EDTA. Homogenates were centrifuged at $1000 \times \mathrm{g}$ for $15 \mathrm{~min}$ at $4 \circ \mathrm{C}$. The supernatant was mixed with glucose-6-phosphate dehydrogenase and NADPH and the activity of hexokinase was determined at $37^{\circ} \mathrm{C}$ for $3 \mathrm{~min}$ at 30 s intervals at $340 \mathrm{~nm}$ (Kinney et al., 2001). Hepatic glycogen was extracted with $30 \% \mathrm{KOH}$, and the yield was estimated by anthrone-sulphuric acid method (Seifter et al., 1950)

The hepatic G-6-Pase (glucose-6-phosphatase) activity was assayed by the method of (Baginsky et al., 1974). Shortly, the glucose-6-phosphate in the liver extract was converted into glucose and inorganic phosphate. The inorganic phosphate liberated was determined with ammonium molybdate; ascorbic acid was used as the reducing agent. Excess molybdate was removed by the arsenite-citrate reagent, so that it could no longer react with other phosphate esters or with inorganic phosphate formed by acid hydrolysis of the substrate. The amount of phosphate liberated per time unit, determined as the blue phosphormolybdous complex at $700 \mathrm{~nm}$, was a measure of the glucose- 6-phosphatase activity. Hepatic hexokinase (EC 2.7.1.1) was determined based on reduction of nicotinamide adenine dinucleotide $\left(\mathrm{NAD}^{+}\right)$through a coupled reaction with glucose-6-phosphate dehydrogenase (Burnstein et al., 1970)

\subsubsection{Serum marker enzymes: SGOT, SGPT, ACP, ALP}

Serum glutamate oxaloacetate (SGOT) and pyruvate (SGPT) transaminases, and acid and alkaline phosphatases (ACP, ALP) levels were determined using standard kits (Eve's Inn Diagnostics, Baroda, India).

\subsubsection{Plasma and hepatic lipid profiles}

From the lipid extract and plasma, the levels of TC and TGs were estimated by using kits (Qualigens Diagnostics) according to the manufacturers' procedures. For the estimation of total cholesterol, $0.1 \mathrm{ml}$ of the lipid extract was evaporated into dryness and $5 \mathrm{ml}$ of ferric chloride-acetic acid reagent was added. To that, $3 \mathrm{ml}$ of concentrated sulfuric acid was added and the absorbance was read after $20 \mathrm{~min}$ at $560 \mathrm{~nm}$ (Zlatkis et al 1953). For the estimation of TGs, $0.5 \mathrm{ml}$ of lipid extract was evaporated into dryness and 0.1 $\mathrm{ml}$ of methanol was added, followed by $4 \mathrm{ml}$ of isopropanol. To this, $0.4 \mathrm{~g}$ of alumina was added, shaken well for $15 \mathrm{~min}$, and centrifuged. To $2 \mathrm{ml}$ of supernatant, $0.6 \mathrm{ml}$ of the saponification reagent $(5 \mathrm{~g}$ of potassium hydroxide in $60 \mathrm{ml}$ of distilled water and $40 \mathrm{ml}$ of isopropanol) and $0.5 \mathrm{ml}$ of acetyl acetone reagent $(0.75$ $\mathrm{ml}$ of acetyl acetone in $60 \mathrm{ml}$ of distilled water and $40 \mathrm{ml}$ of isopropanol) were added and placed in a water bath at $65^{\circ} \mathrm{C}$ for $1 \mathrm{~h}$. All the tubes were cooled and read at $405 \mathrm{~nm}$ (Fossati and Lorenzo, 1982). The HDL-C content in plasma was estimated by using a reagent kit (Qualigens Diagnostics). In tissue, the HDL-C fraction was separated according to the method of (Burnstein et al., 1970) by using heparin-manganese chloride reagent. Cholesterol in the lipoprotein fraction was determined by the method of (Zlatkis et al 1953) using a Qualigens Diagnostics kit. Very low density lipoprotein cholesterol (VLDL-C) and low-density lipoprotein cholesterol (LDL-C) fractions were calculated as follows: VLDL-C $=$ TG/5 and LDL-C $=$ total cholesterol $-($ HDL-C + VLDL-C), respectively.

\subsubsection{Hepatic HMG-CoA reductase and bile acid profile}

The activity of HMG-CoA reductase in the liver was determined (Rao and Ramakrishna, 1975) In brief; equal volumes of tissue homogenate $(10 \%)$ and perchloric acid solution were mixed. After $5 \mathrm{~min}$, the tubes were centrifuged at $3500 \times \mathrm{g}$ for $10 \mathrm{~min}$. To $1 \mathrm{~mL}$ filtrate, $0.5 \mathrm{ml}$ of freshly prepared hydroxylamine reagent (alkaline hydroxylamine reagent in the case of HMG-CoA) was added, mixed, and after $5 \mathrm{~min}, 1.5 \mathrm{ml}$ of ferric chloride was added and shaken well. Readings were taken after $10 \mathrm{~min}$ at $540 \mathrm{~nm}$ against a similarly treated saline-arsenate blank. The ratio between HMG $\mathrm{CoA}$ and mevalonate in the liver was taken as an index of the activity of HMG-CoA reductase. The decrease in the ratio of HMG-CoA/ mevalonate indicated the increased activity of the enzyme. Bile acids in liver, intestine (with content), gallbladder, and feces were extracted with $95 \%$ ethanol once overnight, $80 \%$ ethanol once for $2 \mathrm{~h}$, and methanol/chloroform $(2: 1)$ once for $2 \mathrm{~h}$ at $50{ }^{\circ} \mathrm{C}$. Serum samples were used directly. Total bile acids were determined with a bile acid assay kit (Genzyme Diagnostic, Framingham, MA).

\subsubsection{Faecal cholesterol and bile acid content}

Following the method described by (Kaiek et al 1984) faecal lipids were extracted from faeces $(0.5 \mathrm{~g})$ with a $10 \mathrm{ml}$ mixture of chloroform and methanol $(2: 1 \mathrm{v} / \mathrm{v})$, and the insoluble material was removed with No. 2 filter paper. The filtrate $(0.1 \mathrm{ml})$ was mixed with $0.1 \mathrm{ml}$ of Triton X-100 according to the method of (Carlson and Goldford, 1977) to evaporate the organic solvent from the 
liver or faecal extract. Faecal bile acid was extracted according to the method of (Dewael and Endeman 1977). The dried faeces were first pulverized to a powder. $100 \mathrm{mg}$ of the resulting powder was precisely weighed into a $30 \mathrm{ml}$ glass-stopper test tube, and 1 $\mathrm{ml}$ of $4 \% \mathrm{KOH}$ in ethylene-glycol was added. The mixture was heated at $220{ }^{\circ} \mathrm{C}$ for $15 \mathrm{~min}$. After cooling, $1 \mathrm{ml}$ of $20 \% \mathrm{NaCl}$ solution and $0.2 \mathrm{ml}$ of concentrate $\mathrm{HCl}(37 \%)$ were added. After mixing, $6 \mathrm{ml}$ of diethyl ether was added to the acidified solution, which was then shaken for approximately $1 \mathrm{~min}$. The upper layer was collected after centrifugation at $3000 \mathrm{~g}$ for $5 \mathrm{~min}$. This procedure was repeated three times. These upper diethyl ether layers were combined and evaporated completely at $40{ }^{\circ} \mathrm{C}$. The residue was then dissolved in $1 \mathrm{ml}$ of methanol. Aliquots of this solution were measured enzymatically and spectrophotometrically at 530 $\mathrm{nm}$, using a bile acid analysis kit (No. 450, Sigma, St. Louis, MO, USA).

\subsubsection{Statistical evaluation}

Data are presented as mean \pm standard error of the mean (SEM). One way analysis of variance (ANOVA) followed by Duncan's multiple range test (DMRT) using a commercially available statistics software package (SPSS ${ }^{\circledR}$ for Windows, V. 16.0, Chicago, USA). Results were presented as mean SD. P values $<0.05$ were regarded as statistically significant.

\section{Results}

Exposure to $\mathrm{Cd}(5 \mathrm{mg} / \mathrm{kgbw})$ caused a significant $(\mathrm{p}<0.05)$ decrease in food intake; reduced the body weight gain, at the same time the weight of the liver was increased (Table 1). No significant changes were observed between GSP $(200 \mathrm{mg} / \mathrm{kgbw})$ alone treated and control rats. All these changes induced by $\mathrm{Cd}$ intoxication were significantly $(\mathrm{p}<0.05)$ reverted to normal levels by the oral administration of GSP.

Table 1: Effect of GSP and Cadmium on Food Intake, Body Weight and Liver Weights

\begin{tabular}{llll}
\hline Group & Food intake $(\mathrm{g} /$ day $)$ & Body weight $(\mathrm{g})$ & Liver weight $(\mathrm{g})$ \\
\hline Control & $20.21 \pm 0.25$ & $194.32 \pm 2.15$ & $2.35 \pm 0.06$ \\
Cd & $15.25 \pm 0.32^{\mathrm{a}}$ & $185.36 \pm 3.09^{\mathrm{b}}$ & $2.96 \pm 0.12^{\mathrm{c}}$ \\
GSP & $19.89 \pm 0.15^{\mathrm{a}}$ & $198.01 \pm 3.11^{\mathrm{b}}$ & $2.55 \pm 0.10^{\mathrm{c}}$ \\
Cd+GSP & $18.66 \pm 0.23^{\mathrm{a}}$ & $196.23 \pm 1.96^{\mathrm{b}}$ & $2.40 \pm 0.96^{\mathrm{c}}$ \\
\hline
\end{tabular}

Values are given as mean \pm SD from six rats in each group. ${ }^{\mathrm{a}-\mathrm{c}}$ Values with different superscript letters $(\mathrm{a}-\mathrm{c})$ in the same column differ significantly at $\mathrm{p}<0.05$ (DMRT).

\subsection{Plasma glucose, hepatic glycogen, hepatic} hexokinase and G-6-Pase activities

In biochemical studies Fig 1, Cd (5mg/kgbw) intake significantly elevated $(p<0.05)$ the levels of plasma glucose and hepatic G-6Pase and decreased hepatic glycogen and hexokinase content. GSP $(200 \mathrm{mg} / \mathrm{kgbw})$ supplementation resulted in a significant decline $(p<0.05)$ in plasma glucose and hepatic G-6-Pase levels while increase in both hepatic glycogen content and hexokinase activity. (a)

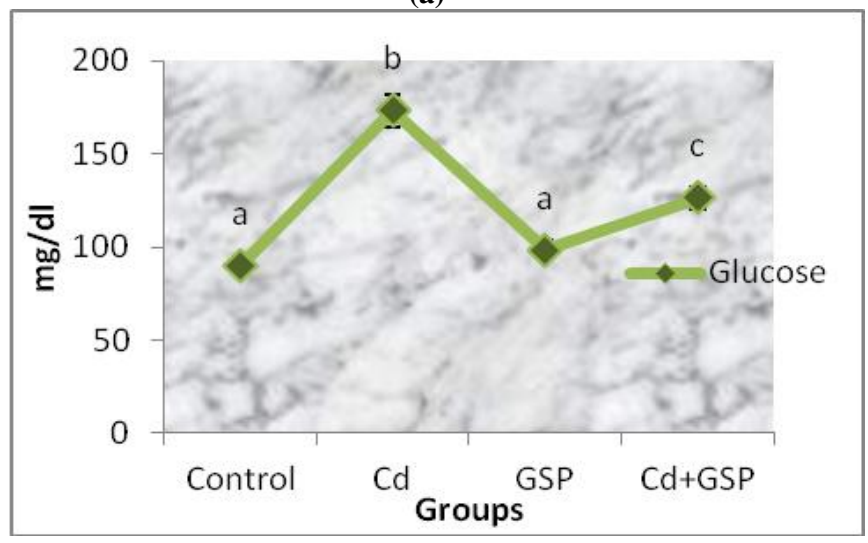

(b)

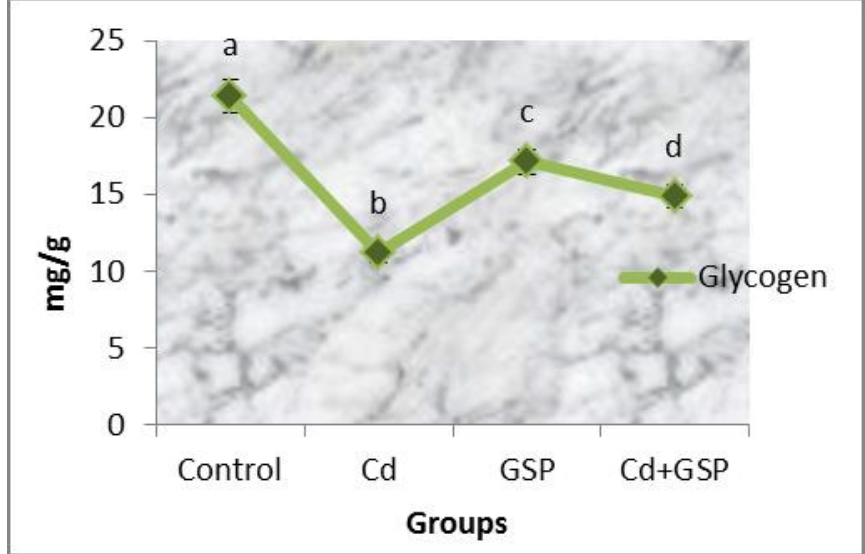

(c)

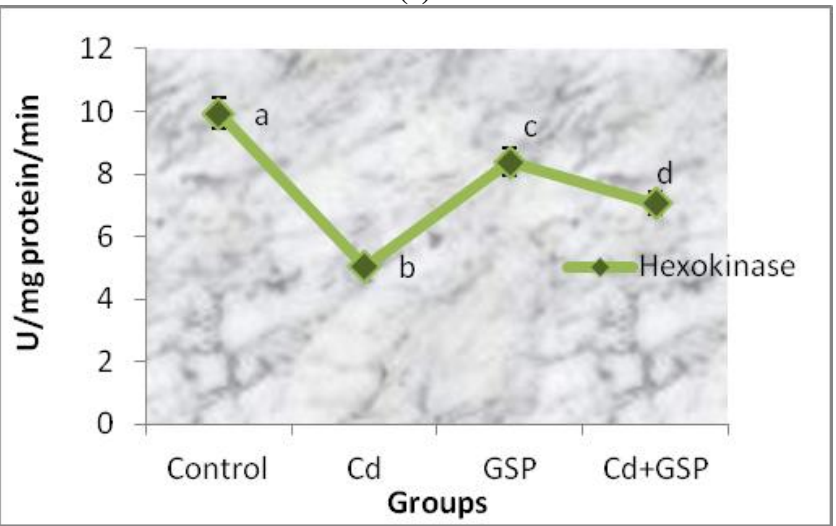

(d)

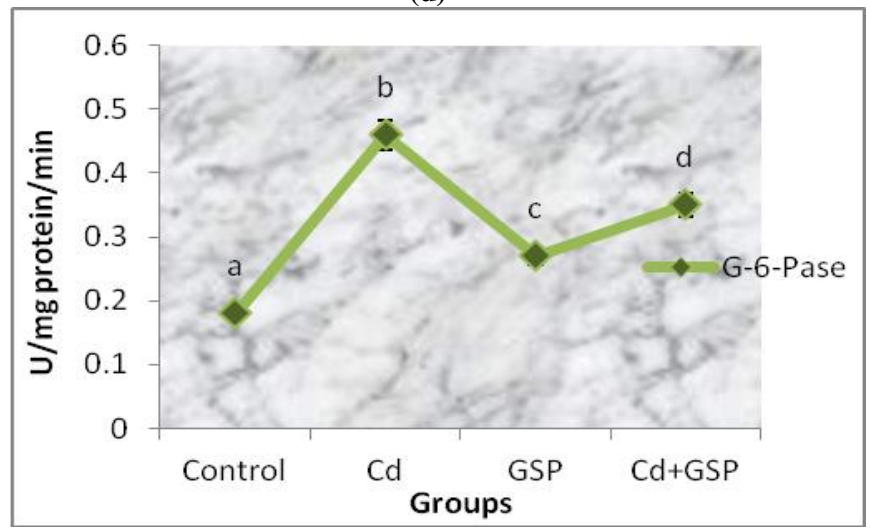

Fig. 1: Effect of GSP on Glucose, Glycogen, Hexokinase and G-6-Pase in control and $\mathrm{Cd}$ treated rats. Values are given as Mean \pm S.D. from six rats in each group. ${ }^{\mathrm{a}-\mathrm{d}}$ Values with different superscript letters (a-d) in the same column differ significantly at $\mathrm{P}<0.05$ (DMRT) 


\subsection{Serum marker enzymes: SGOT, SGPT, ACP and ALP}

Table 2 shows the level of serum hepatic markers in control and experimental rats. Oral administration of $\mathrm{Cd}$ caused abnormal liver function in all rats. Activities of Serum hepato specific marker enzymes such as SGOT, SGPT, ALP, ACP were signed $(\mathrm{p}<0.05)$ increased in $\mathrm{Cd}(5 \mathrm{mg} / \mathrm{kgbw})$ treated rats. Administration of GSP $(200 \mathrm{mg} / \mathrm{kgbw})$ with Cd significantly $(\mathrm{p}<0.05)$ decreased the activities of serum hepatic markers.

Table 2: Changes in the Effect of Serum Hepatic Markers by Cd and GSP

\begin{tabular}{lllll}
\hline Parameter & Control & Cd & GSP & Cd+GSP \\
\hline SGOT(U/I) & $48.06 \pm 0.09$ & $67.02 \pm 0.25^{\mathrm{a}}$ & $54.3 \pm 0.45^{\mathrm{b}}$ & $50.25 \pm 0.15^{\mathrm{bc}}$ \\
SGPT(U/I) & $31.11 \pm 0.72$ & $43.51 \pm 0.96^{\mathrm{a}}$ & $39.43 \pm 0.56^{\mathrm{b}}$ & $30.96 \pm 0.54^{\mathrm{bc}}$ \\
ALP (U/I) & $61.22 \pm 0.57$ & $82.31 \pm 0.32^{\mathrm{a}}$ & $65.1 \pm 0.42^{\mathrm{c}}$ & $62.52 \pm 0.1^{\mathrm{b}}$ \\
ACP(U/I) & $40.3 \pm 0.1$ & $71.43 \pm 0.26^{\mathrm{a}}$ & $47.05 \pm 0.65^{\mathrm{b}}$ & $50.03 \pm 0.14^{\mathrm{c}}$ \\
\hline
\end{tabular}

Values are given as mean \pm SD from six rats in each group. ${ }^{\text {a-c }}$ Values with different superscript letters (a-c) in the same column differ significantly at $\mathrm{p}<0.05$ (DMRT)

\subsection{Plasma and hepatic lipid profiles}

In comparison to controls, rats poisoned with $\mathrm{Cd}(5 \mathrm{mg} / \mathrm{kgbw})$ (Fig 2) displayed lower HDL-cholesterol concentrations, higher levels of LDL-C, VLDL-C in plasma $(\mathrm{p}<0.05)$. The addition of GSP $(200 \mathrm{mg} / \mathrm{kgbw})$ resulted in a significant reduction of $\mathrm{Cd}$ hypercholesterolaemia and enhanced the plasma HDL-C level. Whereas in hepatic lipid profile $\mathrm{Cd}$ exposed rats registered higher levels of TL, TG and TC as compared to GSP and the control group (Fig 3), while GSP restored the levels to normal.

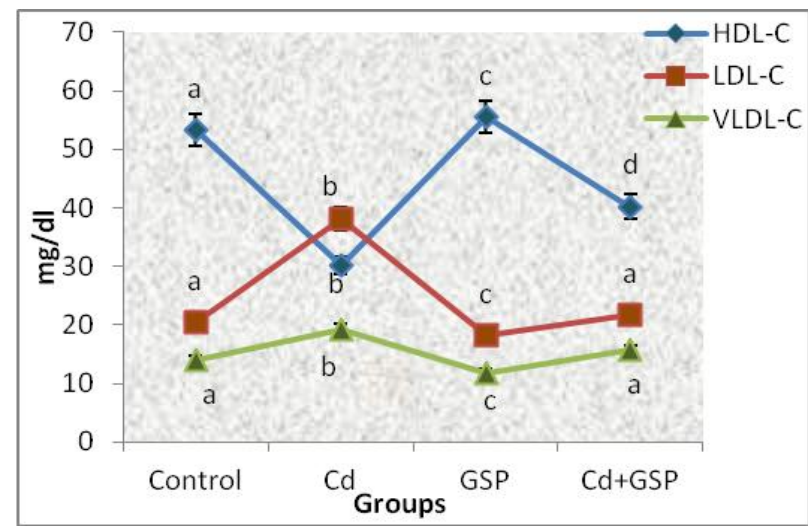

Fig. 2: Effect of GSP on Serum Lipoproteins in control and Cd treated Rats. Values are given as Mean \pm S.D. from six rats in each group. ${ }^{\text {a-d }}$ values with different superscript letters (a-d) in the same column differ significantly at $\mathrm{P}<0.05$ (DMRT).

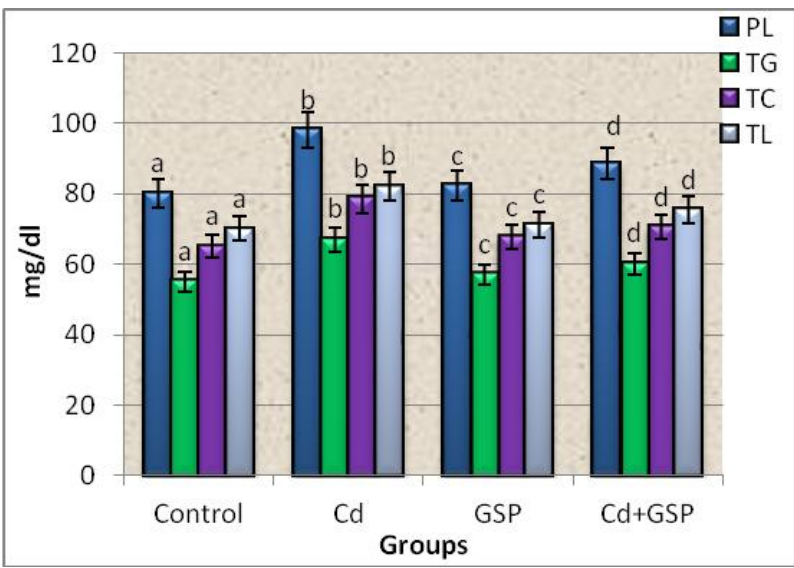

Fig. 3: Effects of GSP on Plasma Lipids (PL), Hepatic Total Lipids (TL) Triglycerides (TG) and Total Cholesterol (TC) in control and Cd treated Rats. Values are given as Mean \pm S.D. from six rats in each group. ${ }^{\mathrm{a}-\mathrm{d}}$ Values with different superscript letters (a-d) in the same column differ significantly at $\mathrm{P}<0.05$ (DMRT).

\subsection{Hepatic HMG-CoA reductase and bile acid profile}

In Fig 4, Cd (5mg/kgbw) treated rats showed significant $(\mathrm{P}<0.05)$ increase in the activity of HMG-CoA reductase in the plasma as compared to normal control rats. A significant $(\mathrm{P}<0.05)$ decrease in the bile acid content was noted in Cd treated rats as compared to control group. Pre-treatment of GSP $(200 \mathrm{mg} / \mathrm{kgbw})$ significantly $(\mathrm{P}<0.05)$ decreased the activity of this enzyme in the plasma and liver compared to $\mathrm{Cd}$ treated rats also increase in the bile acid content was observed in GSP pretreated rats. A lower ratio of HMG-CoA/mevalonate indicated higher enzyme activity and vice versa.

\subsection{Faecal cholesterol and bile acid content}

Cd treated rats $(5 \mathrm{mg} / \mathrm{kgbw})$ showed higher levels of faecal cholesterol and bile acid as compared to the normal group, whereas the GSP $(200 \mathrm{mg} / \mathrm{kgbw})$ group significantly restored the faecal cholesterol (Fig 5) and bile acid contents (Fig 4) when compared to Cd treated groups.

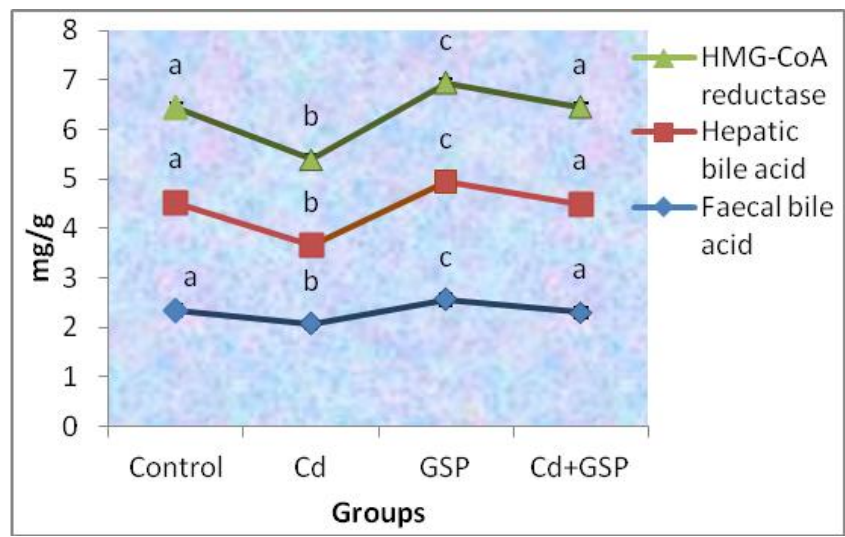

Fig. 4: Effects of GSP on Hepatic and Faecal Bile acids and HMG-CoA reductase activity in $\mathrm{Cd}$ treated Rats. Values are given as Mean \pm S.D. from six rats in each group. ${ }^{\mathrm{a}-\mathrm{c}}$ Values with different superscript letters (ac) in the same column differ significantly at $\mathrm{P}<0.05$ (DMRT).

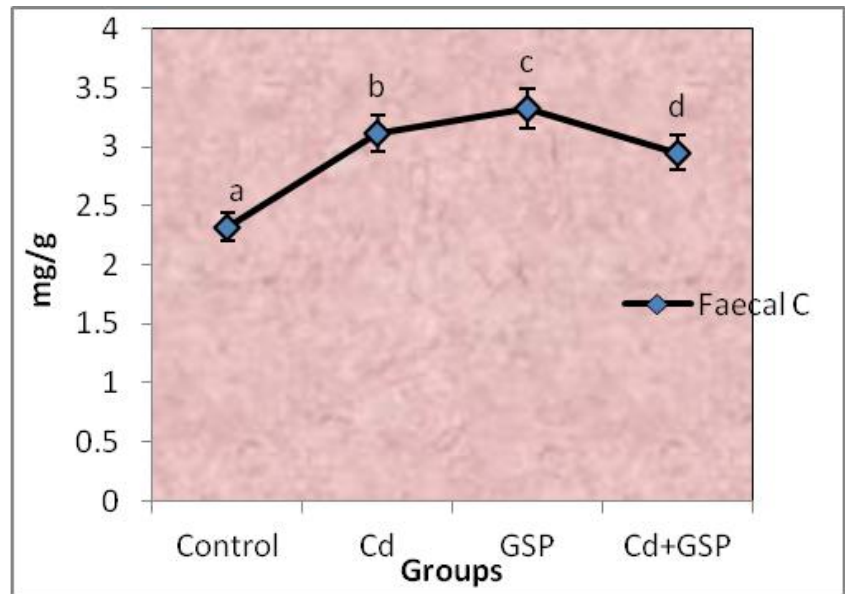

Fig. 5: Effects of GSP on Faecal Cholesterol in control and Cd treated Rats Values are given as Mean \pm S.D. from six rats in each group. ${ }^{\text {a-d }}$ Values with different superscript letters (a-d2) in the same column differ significantly at $\mathrm{P}<0.05$ (DMRT)

\section{Discussion}

The present study clearly demonstrates the restorative effects of GSP, as it normalized carbohydrate, lipid and antioxidant profiles in $\mathrm{Cd}$ exposed rats. Weight gain depends on availability of nutrients. Therefore, the observed reduction in weight gain is due to the decrease in food intake, or due to the overall increased degeneration of lipids and proteins as a result of $\mathrm{Cd}$ toxicity (Erdogan et al., 2005) and the administration of $\mathrm{CdCl}$ led 
to selective accumulation of $\mathrm{Cd}$ in certain organs especially liver. The decreased weight gain and increase in the liver weight of rats observed in this study is consistent with some previously published reports (Milton and Shagirtha, 2013). On the other hand, inclusion of GSP in the diet increased feed consumption with increased body weight and normalizes the liver weight, reflecting the efficacy of GSP in regulating appetite, normalizing the digestion and assimilatory process in $\mathrm{Cd}$ intoxicated rats.

Glucose intolerance observed in $\mathrm{Cd}$ intoxicated rats is mediated through different mechanisms. One possible mechanism for the development of impaired glucose tolerance in $\mathrm{Cd}$ intoxicated rats impairs insulin synthesis. Cd intoxication in the rat was associated with a decreased pancreatic secretory activity as evidenced by lowering insulinogenic indices and marked inhibition of phentolamine-stimulated insulin release. Cd-induced hypoinsulinemia is attributed to an adrenaline response since adrenaline is known to inhibit insulin secretion (Kim and $\mathrm{Na}$. 1991) When the concentration of glucose in the blood rises because of $\mathrm{Cd}$, glucose enters hepatocytes and binds to the regulatory site of glycogen phosphorylase-a, causing a conformational change that exposes the phosphorylated residues to dephosphorylation by phosphorylase-a phosphatase. Glycogen phosphorylase acts as the glucose sensor of liver, slowing the breakdown of glycogen whenever the level of blood glucose is high. Hexokinase, which catalyzes the entry of free glucose into the glycolytic pathway, is another regulatory enzyme. Glucose entering myocytes from the blood (in which the glucose concentration is 4 to $5 \mathrm{mM}$ ) produces an intracellular glucose concentration high enough to saturate hexokinase, so that it normally acts as its maximal rate. Whenever the concentration of glucose-6phosphate in the cell rises above its normal level, hexokinase is temporarily and reversibly inhibited, bringing the rate of glucose6 phosphate formation into balance with the rate of its utilization and re-establishing the steady state. The pancreatic $\beta$ cells, which are responsible for the release of insulin when blood glucose levels rise above normal, also contain glucokinase and the inhibitory regulator protein. Therefore the application of glucose and glucose-6-phosphate increases with the decrease of hepatic glycogen and hexokinase in $\mathrm{Cd}$ treated rats. On the other hand the plasma insulin and glucose responses to fruit depended on the fiber and glucose content. Oleanolic acid and aleanolic aldehydes present in grape seed have insulin secretory activities (Zhang et al., 2004) GSP, chromium polynicotinate, and zinc monothionine combinations enhance insulin sensitivity and lowers levels of glycosylated proteins (Preuss et al., 2001). Flavonoids and epicatechin isolated from grapes stimulate $\beta$-cell regeneration and ameliorate chemically induced increased glucose level in rats (Kakkar et al 1984). Recently, (Xu et al., 2008) reported that feeding an extract of grape seed proanthocyanidins down-regulates the receptor for glycation end products. It materializes for that reason metabolite present in GSP synergistically declined the levels of glucose and hepatic G-6-Pase while enhancing the activity of hexokinase and improving glycogen content. Our results concur with (Suwannaphet et al 2010) that GSP prevents body weight gain, hyperglycemia and hypoinsulinemia due to its ability to attenuate the impairment of insulin-stimulated glucose disposal in rats with insulin resistance.

Cd intoxicated rats developed hepatic damage which was evident by the increase in the enzyme activities as the levels of SGPT, SGOT, ALP and ACP significantly increased in Cd treated rats. In a study on rats, the significant rise in serum SGPT and SGOT levels in the $\mathrm{Cd}$ group relates to excessive accumulation of amino acids (glutamate and alanine) in the serum of rats as a result of amino acid mobilization from protein stores. The higher levels of SGPT and SGOT, give rise to a high concentration of glucose. These enzymes are active in the absence of insulin because it increases the availability of amino acids in high glucose level which is responsible for ketogenesis and gluconeogenesis (Chalasani et al., 2004). In other words, the gluconeogenic action of SGPT and SGOT plays the role in providing new supplies of glucose from other sources such as amino acids (Hussein et al., 2006). Treat- ments with the GSP restore the SGOT and SGPT levels to normal as compared to $\mathrm{Cd}$ treated rats. GSP through its anti-lipid peroxidation activity causes stabilization of liver membranes and prevents the leakage of liver enzymes via hydrogen donation from the phenol to the free radical containing compounds. The typical base structure with ring stability helps support the free radical that it is left with and therefore does not react again to initiate oxidation. This indicates that GSP has the capacity to provide protection against rat hepatic tissue. In this context, the protective effect of GSP has already been reported (Baskaran and Anuradha, 2013).

The observed increase in the levels of the plasma VLDL-C and LDL-C with a decreased level of HDL-C in Cd intoxicated rats clearly reflects the abnormalities in lipoprotein metabolism. In $\mathrm{Cd}$ treated rats, lowered level of plasma HDL-C implies the altered metabolism of the major HDL apoprotein A-I (Huesca et al 2002). The overproduction of hepatic VLDL-C and impaired catabolism of TG-rich particles in Cd toxicity may lead to hypertriglyceridemia. HDL enables lipids like cholesterol and triglycerides to be transported within the water-based bloodstream. In healthy individuals, about thirty percent of blood cholesterol is carried by HDL. Blood tests typically report HDL-C level, i.e. the amount of cholesterol contained in HDL particles. It is often contrasted with low density or LDL cholesterol or LDL-C. HDL particles are able to remove cholesterol from within artery atheroma and transport it back to the liver for excretion or re-utilization, which is the main reason why the cholesterol carried within HDL particles (HDL-C) is sometimes called "good cholesterol" (despite the fact that it is exactly the same as the cholesterol in LDL particles) (Walter, 2007). The changes in the activity of HMG-CoA reductase by $\mathrm{Cd}$ depress the LDL receptor gene expression. Defects in LDL receptor interfere with cholesterol uptake from the blood stream, which in turn causes excess cholesterol synthesis in the liver and high levels of plasma cholesterol and LDL-C (Kantola et al 1998). On the other hand, the hypolipidemic effect of GSP may occur through inhibition of VLDL-C secretion by the liver, which is mainly due to a reduction in the bioavailability of lipids, mainly TG or the reduction in the availability of free fatty acids in the liver. GSP markedly inhibited pancreatic lipase with p-NPP, it was found that the degree of polymerization of oligomeric proanthocyanidins caused a marked inhibition of pancreatic lipase. Pancreatic esterase plays a pivotal role in hydrolyzing dietary cholesterol esters (Brodt et al., 1995). Generally hydrolysis of cholesterol ester in the lumen of the small intestine is catalyzed by pancreatic cholesterol esterase which liberates free cholesterol. Moreover, it enhances the incorporation of cholesterol into mixed micelles (Myers et al 1995). Since GSP inhibits the absorption of TC and bile acids by decreasing micellar cholesterol solubility. This inhibitory action may enhance to control the bioavailability of dietary cholesterol esters and limitation of absorption of free cholesterol into blood circulation. Another suggestion is the delay and inhibition of dietary fat and cholesterol absorption and a reduction in the chylomicron secretion by enterocytes (Blade et al 2010). The Antilipidemic effect of GSP can also be attributed to its ability to enhance the activity of enzymes involved in bile acid synthesis and its excretion leading to a decrease in the TC and TG levels (Sethupathy et al., 2002). GSP altered several obesityassociated parameters including fasting blood glucose and leptin levels and enhanced $\beta$-cell function. Leptin is a hormone produced by adipocytes (macdougald et al., 1995). Which reduces triglyceride formation in various organs by increasing free fatty acid (FFA) oxidation and decreasing its esterification to triglyceride, thus, it reduces insulin resistance and $\beta$-cell dysfunction, which is known to lead to obesity and associated diabetes (Wu and Prior, 2005). HMG-CoA reductase is an enzyme of much importance in lipogenesis since it catalyzes the rate-limiting step in cholesterol biosynthesis. An increase in the biosynthesis of cholesterol generally takes place in the endoplasmic reticulum of hepatic cells and begins with acetyl- CoA. Acetyl-CoA and acetoacetyl-CoA are converted to 3-hydroxy- 3-methylglutaryl-CoA (HMG-CoA) by HMG-CoA synthase. HMG-CoA is then converted to mevalonate by HMG-CoA reductase (HMGR). This reaction is completed 
with the aid of NADPH. In the present study HMG-CoA reductase activity was indirectly measured in terms of the ratio between HMG CoA and mevalonate. We have observed a significant increase in the activity of the HMG-CoA reductase in the plasma and liver of Cd-intoxicated rats. Enhanced activity of HMG-CoA reductase is due to increased lipid peroxidation in Cd-treated rats. Cd-induced liberation of inflammatory cytokines and interleukins are reported to increase the expression of cholesterogenic enzymes, including HMG-CoA reductase and suppress cholesterol $7 \alpha$-hydroxylase, a catabolic enzyme of cholesterol the liver (Harstad and Klassen, 2004). Cd induced changes in the activity of hydroxy 3-methylglutaryl-coenzyme A (HMG-CoA) reductase, alters cholesterol as well as all lipid metabolisms. Our result is in tune with the previous reports of (Prabu et al 2010). Bile flow significantly decreased in $\mathrm{Cd}$ treated rats, suggesting that $\mathrm{Cd}$ af fects hepatic transport and biliary secretory processes well before causing significant plasma membrane damage to hepatocytes. However the possibility is also that $\mathrm{Cd}$ may directly affect the bile duct by causing inflammation or damage to biliary epithelial cells, thus obstructing bile flow and consequently causing liver cholestasis thus decreasing its concentration in Cd treated rats. On the other side pretreatment with GSP significantly decreased the activity of HMG CoA reductase in Cd-induced rats. HMG-CoA reductase inhibitors are known to decrease the secretion of VLDL and LDL levels. Further decrease in cholesterol levels in GSP treatment is correlated to the decreased activity of HMG-CoA reductase. In this regard, proanthocyanidin A-2 inhibits HMGCoA reductase activity in rats. Bile acids after conjugation with glycine and taurine are secreted into the duodenum. Once secreted into the small intestine, added solubility aids in the bile salt function is by preventing passive re-absorption once secreted into the small intestine. As a result, the concentration of bile acids/salts in the small intestine can stay high enough to form micelles and solubilize lipids. "Critical micellar concentration" refers to both an intrinsic property of the bile acid itself and the amount of bile acid necessary to function in the spontaneous and dynamic formation of micelles (Hofmann and Hagey, 2008). GSP increase bile acid by upregulating the enzyme cholesterol $7 \alpha$-hydroxylase (CYP7A1) with a slight downregulation of LXR- $\alpha$. Also binding bile acids by forming insoluble complexes in the intestine and increasing their fecal excretion have been hypothesized as a possible mechanism of lowering plasma cholesterol levels. This phenomenon consequently releases a feedback inhibitory mechanism by inhibiting bile acid synthesis. As a result, a greater amount of cholesterol is converted to bile acids to maintain a steady level in the blood circulation (Insull, 2006). As a result, GSP exhibits the strongest binding capacity against glycodeoxycholic acid, whereas it's slightly bound to taurocholic acid and taurodeoxycholic acid, indicating that GSP increases fecal bile acid excretion, resulting in the reduction of plasma cholesterol level.

\section{Conclusion}

In conclusion, GSP has beneficial and protective effect agains hyperglycemia, hyperlipidemia, and peroxidation associated with cadmium induced metabolic dysfunction in rats. The improvement in carbohydrate, lipid, and antioxidant metabolism could be due to the metabolites present in GSP in addition to its antioxidant properties. GSP acted synergistically to reduce the oxidative stress caused by consumption of $\mathrm{Cd}$. Further studies are necessitated to discover the role of GSP in preventing Cd caused alterations in the metabolism of rats. In light of our observation, we conclude that GSP can be used as a component in food to promote the health of people.

\section{Acknowledgement}

The Authors would like thank to the Head of the Department of Zoology, Annamalai University for providing laboratory facilities and generous support.

\section{References}

[1] ATSDR (Agency for Toxic Substance and Disease Registry) (2005) Draft Toxicological Profile for Cadmium. Department of Health and Humans Services, Public Health Service, Centers for Disease Control, Atlanta, GA, USA.

[2] Baginsky ES, Foa PP, Zad B (1974). Glucose-6-phosphatase In: Bergemeyer H.U., editor. Methods of enzymatic analysis. New York, Academic; 2: 788-92.

[3] Baskaran Yogalakshmi1, Carani Venkatraman Anuradha (2013). Role of Grape Seed Proanthocyanidins in the Suppression of High Calorie Diet-Induced Hepatic Injury and Apoptosis. Sci and Res; 2(7): 406411.

[4] Blade C, Arola L \& Salvad MJ (2010). Hypolipidemic effects of proanthocyanidins and their underlying biochemical and molecular mechanisms. Mol. Nutr. Food Res; 54: 37-59.

[5] Brandstup N, Kirk JE, Bruni C (1957). Determination of hexokinase in tissues. J. Gerontol; 12:166-71.

[6] Brodt-Epply J., White P., Jenkins S., Hui D.Y. (1995). Plasma cholesterol esterase level is a determinant for an atherogenic lipoprotein profile in normolipidemic human subjects. Biochim biophys acta; 1272(2): 69-72.

[7] Burnstein M., Scholnic M.R., Mortin R. (1970). Rapid method of isolation of lipoprotein from human serum by precipitation of polyanion. J. Lipid Res; 11:583-87.

[8] Carlson, S. E., \& Goldford, S (1977). A sensitive enzymatic method for determination of free and esterified tissue cholesterol. Clinica Chimica Acta; 79: 575-582.

[9] Chalasani N, Aljadhey H, Kesterson J, Murray MD, Hall SD (2004). A patient with elevated liver enzymes is not at higher risk for statin hepatotoxicity. Gastroenterology; 126: 1287-1292.

[10]Del Bas JM, Fernández-Larrea J, Blay M, Ardèvol A, Salvadó MJ, Arola L, et al (2005). Grape seed procyanidins improve atherosclerotic risk index and induce liver CYP7A1 and SHP expression in healthy rats. FASEB J.; 19(3): 479-81.

[11]Dewael J, Raaymakers CE, \& Endeman HJ (1977). Simplified quantitative determination of total fecal bile acids. Clinica Chimica Acta; 79: 465-470.

[12]Engelbrecht AM, Mattheyse M, Ellis B, Loos B, Thomas M, Smith R, Peters S, Smith C, Myburgh K (2007). Proanthocyanidin from grape seeds inactivates the PI3-kinase/PKB pathway and induces apoptosis in a colon cancer cell line. Cancer Lett. 258: 144-153.

[13]Erdogan Z, Erdogan S, Celik S, Unlu V (2005). Effects of ascorbic acid on cadmium-induced oxidative stress and performance of broilers Biol. Trace Elem. Res.; 104: 19-31.

[14]Fossati P \& Lorenzo P (1982). Serum triglycerides determined colorimetrically with an enzyme that produces hydrogen peroxide. Clin. Chem.; 28: 2077-80.

[15]Harborne JB \& Mabry TJ (1982). The flavanoids: advances in research. New York: Chapman and Hall.

[16]Harstad EB \& Klaassen CD (2004). Acute cadmium exposure enhances AP-1 DNA binding and induces cytokines expression and heat shock protein 70 in HepG2 cells. Toxicology; 197: 213-28.

[17]Hofmann AF \& Hagey LR (2008). Bile acids: chemistry, pathochemistry, biology, pathobiology, and therapeutics. Cell Mol. Life Sci.; 65: 2461- 2483

[18]Huesca-Gomez C, FrancoM, Luc G, Montano LF, Masso F, PosadasRomero (2002). Chronic hypothyroidism induces abnormal structure of high-density lipoproteins and impaired kinetics of apolipoprotein A-I in the rat. Metabolism; 51: 443-50

[19]Hussein HM, EI-Sayed EM, Said AA (2006). Antihyperglycemic, Antihyperlipidemic and Antioxidant Effects of Zizyphus spina christi and Zizyphus jujuba in Alloxan Diabetic Rats. Int. J. Pharm; 2: 563570 .

[20]Insull W Jr (2006). Clinical utility of bile acid sequestrants in the treatment of dyslipidemia: a scientific review. South Med. J.; 99: 257 273.

[21]Kaiek HD, Stellaard F, Kruis W, Paumgartner G (1984). Detection of increased bile acid content in simple stool samples. Clin. Chim. Acta; 140: 85-90.

[22]Kakkar P, Das B, Viswanathan PN (1984). A modified spectrophotometric assay of superoxide dismutase. Ind. J. Biochem. Biophys; 2 : 130-2.

[23] Kantola T, Kivisto KT, Neuvonen PJ (1998). Grapefruit juice greatly increases serum concentration of lovastatin and lovastatin acid. Clin. Pharmacol Ther.; 63: 397-402.

[24]Kim, E \& Na, KJ (1991). Effect of sodium dichromate on carbohydrate metabolism. Toxicol Appl Pharmacol; 110: 251-258. 
[25]Kinney LaPier T. L. \& K. J. Rodnick (2001). Effects of aerobic exercise on energy metabolism in the hypertensive rat hear. Physical Therapy; 81:1006-1017.

[26]Larregle EV, SM Varas, LB Olivreos, LD Martinez, R Anton, E Marchevsky, MS Gimenez (2008). Lipid metabolism in liver of rat exposed to cadmium. Food Chem.Toxicol; 46: 1786-1792.

[27]MacDougald, OA, Hwang, CS, Fan H, Lane MD (1995). Regulated expression of the obese gene product (leptin) in white adipose tissue and 3T3-L1 adipocytes. Proc Natl Acad Sci USA; 92 9034-9037.

[28]Milton Prabu S, K.Shagirtha, and J Renugadevi (2010). Amelioration of Cadmium-Induced Oxidative Stress, Impairment in Lipids and Plasma Lipoproteins by the Combined Treatment with Quercetin and $\alpha$-Tocopherol in Rats. J. Food Sci.; Vol. 75, NR.7.

[29]Milton S Prabu \& Shagirtha K (2013). Caffeic avid potentially attenuates cadmium intoxicated oxidative stress mediated hepatotoxicity in rats. Photon; 139: 141-152.

[30]Myers-payne sc, Hui dy, Brockman hl, Chroedar f (1995). Cholesterol esterase: a cholesterol transfer protein. Biochem.; 34(3942): 39-47.

[31]Nazimabashir, Vaihundam Manoharan \& Selvaraj Milton Prabu (2014). Protective role of grape seed proanthocyanidins against cadmium induced hepatic dysfunction in rats. Toxicol. Res.; 3, 131-141

[32]Preuss HG, Montamarry S, Echard B, Scheckenbach R, Bagchi D (2001). Long-term effects of chromium, grape seed extract, and zinc on various metabolic parameters of rats. Mol. Cell Biochem.; 223: 95102.

[33]Rao AV \& Ramakrishnan S (1975). Indirect assessment of hydroxymethylglutaryl $\mathrm{CoA}$ reductase (NADPH) activity in liver tissue. Clin Chem; 21(10): 1523-5.

[34]Robert L Godeau G, Gavignet-Jeanninc, Groult N, Six C, Robert AM (1990). The effect of procyanidolic oligomers on vascular permeability .a study using quantitative morphology. Pathol. Biol. (Paris); 38: 608-16.

[35] Sarkar S, Yadav P, Trivedi R, Bansal AK \& Bhatnagar D (1995). Cadmium induced lipid peroxidation and status of antioxidant systems in rat tissue. J.Trace. Elem. Med. Biol; 9: 144-149.

[36] Seifter S, Dayton S, Novic B, Muntwyler E (1950). Estimation of glycogen with anthrone reagent. Arch Biochem; 25: 191-200.

[37] Sethupathy S, Elanchezhiyan C, Vasudevan K, Rajagopal G (2002). Antiatherogenic effect of taurine inhigh fatdiet fed rats. Indian J. Exp. Biol.; 40: 1169-72.

[38]Stohs, S.J., Bagchi, D., Hassoun, E., Bagchi, M (2000). Oxidative mechanisms in the toxicity of chromium and cadmium ions. J. Environ. Pathol. Toxicol. Oncol; 19: 201-213.

[39]Suwannaphet W, Meeprom A, Yibchok-Anun S, Adisakwattana S (2010). Preventive effect of grape seed extract against high-fructose diet-induced insulin resistance and oxidative stress in rats. Food Chem Toxicol; 48(7): 1853-7.

[40]Timbrell J (2000). Principles of biochemical toxicology 3rd ed. London. Taylor and Francis.

[41]Walter MF (2007). The role of hypertriglyceridemia in atherosclerosis. Curr. Atheroscler. Rep.; 9: 110-5.

[42]Wu X \& Prior RL (2005). Systematic identification and characterization of anthocyanins by HPLC-ESI-MS/MS in common foods in the United States: fruits and berries. J. Agric. Food Chem.; 53: 2589-2599.

[43]Xu L, Li B, Cheng M, et al (2008). Oral administration of grape seed proanthocyanidin extracts downregulate RAGE dependant nuclear factor-kappa BP65 expression in the hippocampus of streptozotocin induced diabetic rats. Exp. Clin. Endocrinol Diabetes; 116: 215-224.

[44]Zhang Y, Jayaprakasam B, Seeram NP, Olson LK, DeWitt D, Nai MG (2004). Insulin secretion and cyclooxygenase enzyme inhibition by Cabernet Sauvignon grape skin compounds. J. Agric. Food Chem.; 52: 228-233.

[45] Zlatkis A, Zak B, Boyle GJ (1953). A simple method for determination of serum cholesterol. J. Clin. Med.; 41: 486-92. 